\title{
Outside the Classroom: Gender Differences in Extracurricular Activities of Engineering Students
}

\author{
Debbie Chachra, Helen L. Chen, Deborah Kilgore, and Sheri Sheppard \\ debbie.chachra@olin.edu, hlchen@stanford.edu, kilgored@u.washington.edu, sheppard@stanford.edu
}

\begin{abstract}
Data from the Academic Pathways Study, a component of the NSF-funded Center for the Advancement of Engineering Education, were used to investigate engineering student involvement in extracurricular activities. The study design used a variety of methods: the results presented here are from longitudinal and crosssectional surveys of engineering students as well as interviews with graduating seniors. Quantitative data from both surveys suggest that women place higher importance on extracurricular activities than their male counterparts, as well as reporting higher participation in both engineeringrelated and non-engineering-related extracurricular activities. In addition, the importance of non-engineering extracurricular activities and the level of involvement of engineering-related extracurricular activities increases over four years of engineering education for women. For men, an increase with time was only observed for involvement in engineering-related activities. Results from the interviews corroborate the quantitative findings as well as suggesting some intriguing differences between genders: for example, that women may be more likely to take on leadership roles and men more likely to be involved in activities which involve design or 'hands-on' work.
\end{abstract}

Index Terms - engineering, extracurricular activities, gender, student development

\section{BACKGROUND}

Student engagement in extracurricular activities, and the integration of these activities with academics, can be critical factors influencing student persistence ([1-3] as reviewed in [4]). As well, there is evidence linking extracurricular and social involvement to career choices, goals and plans as well as success in future employment and earnings. The relationship between student social and extracurricular involvement and general cognitive skills and intellectual skills is well documented [4]. Increasing student engagement in extracurricular activities is therefore considered a best practice to foster student learning [5].

Recent work has shown that engineering students engage in extracurricular activities to a similar degree as students in other majors [6], which is counter to popular perception. Together with the persistent gender gap between men and women in engineering and other STEM fields, this provides the motivation to explore the involvement of engineering students, of both genders, in extracurricular activities. We are exploring the relationship of students to these extra- and co-curricular activities, using data from the Academic Pathways Study (APS), which is part of the NSFfunded Center for the Advancement of Engineering Education (CAEE). The APS is a multi-university, longitudinal study that focuses on the experiences of students as they move into, through, and out of engineering education [7]. One goal of the APS research is to systematically examine how engineering students navigate their education, and how engineering skills and identity develop during their undergraduate careers. To achieve it, researchers have been using a variety of methods, including ethnography, surveys, interviews, design tasks, and analyses of academic transcripts [7, 8]. There are several models of mixed-methods research and the one used here has been termed a "concurrent triangulation" design, where the integration of the results from the various methods occurs during the interpretation phase [9], enabling researchers to address a broad range of research questions directed toward discerning complex phenomena like student learning and development [10]. The advantage of this approach for our purposes is that it combines the power of quantitative methods to identify a phenomenon that occurs across a larger sample of students with the power of qualitative methods to provide a robust description of the phenomenon.

Data presented here are from three sources. As well as ethnographic interviews conducted with individual students, we present results from two survey instruments which represent the collective work of the APS research-the Persistence in Engineering (PIE) survey and the Academic Pathways of People Learning Engineering Survey (APPLES). At their core, the PIE and APPLE instrument share a common set of variables or constructs that relate to the factors that influence undergraduate persistence in the engineering major [11]. The PIE survey was administered longitudinally to a small cohort of engineering students, who also participated in other elements of the APS study, while the APPLES study was administered to a stratified population of engineering students nationwide.

\section{QUANTITATIVE FINDINGS: PIE SURVEY}

The Persistence in Engineering (PIE) Study involved the longitudinal administration of a survey to probe student attitudes and behaviors. The study was administered seven times to a cohort of students at four engineering schools, throughout four years of their engineering education. These 


\section{Session T1A}

same students participated in a series of interviews and design tasks, providing us with a rich dataset of the undergraduate engineering student experience and a comprehensive view of how students develop as engineers.

Survey data were used in order to investigate population-level differences by gender. Data were derived from the Persistence in Engineering Study (PIE), a component of the Academic Pathways Study. This survey was administered longitudinally to a cohort of 40 students at each of the four CAEE institutions ( $\mathrm{n}=160$ in total). All of the first-year students who entered the study were either admitted to an engineering program or were intending to major in engineering, and the resulting sample discussed here consists of those same students who entered the study in their first year and persisted in engineering until graduation. It should also be noted that the student participants in the APS were what we consider "traditional" students: those who enter college as very young adults and attend full-time until the completion of their degrees. Full details of the development, administration, and preliminary results of the survey can be found elsewhere [12, 13].

Responses to two related constructs, both consisting of a single item (construct) are presented here. The two constructs are as follows:

\begin{abstract}
Importance of involvement in extracurricular activities: Some people are involved in non-engineering activities on or off campus, such as hobbies, civic or church organizations, campus publications, student government, social fraternity or sorority, sports, etc. How important is it for you to be involved in these kinds of activities? Response options: not important, somewhat important, very important, essential
\end{abstract}

Frequency of involvement in extracurricular activities: How often are you involved in the kinds of non-engineering activities described above?

Response options: never, rarely, occasionally, frequently.

The PIE survey was an evolving instrument, and it should be noted that, after the third administration (middle of junior year), the first of these items was simplified, and the second item was amended to reflect this.

How important is it for you to be involved in non-engineering activities?

How often are you involved in these kinds of non-engineering activities?

The response options remained unchanged.

The respondents were limited to those who completed their engineering degree in four years (persisters), which included 45 females and 62 males, for a total of 107 persisters. The responses were linearly normalized to a scale from 0 to 1 . A repeated-measures analysis of variance, using gender and administration (time) as the factors, was then performed with the data. The ANOVA provides information on overall differences between men and women's responses, effect of administration, and any interaction effect. If the overall ANOVA was statistically significant for either gender or time, it was followed by post hoc t-tests to observe differences in gender at each timepoint, or an ANOVA followed by Least Square Difference tests to determine differences between administrations for a given gender. Note that, while the repeated-measure ANOVA is an extremely powerful statistical technique, it can only be used for complete sets of data: each respondent must have answered all the items on each survey. Some of the persisters did not answer all items belonging to one construct, but answered all the items for another. As a result, the exact number of participants varies slightly with each construct.

Graphs of the responses to these two constructs are given below. The mean values are presented, with error bars depicting the standard error of the mean. Note that along the $\mathrm{x}$-axis, 'time,' is an approximation. Due to the exigencies of administering surveys at different sites, the timing of each administration varies slightly by institution.

When the entire time range was considered, females rated the importance of extracurricular activities significantly higher than their male counterparts $(\mathrm{p}<0.05$ for gender by ANOVA), although the responses from males and females were only statistically significant at the start of the second (sophomore) year $(\mathrm{p}<0.05)$.

Unsurprisingly, given the greater importance women place on non-engineering activities, they report engaging in these activities at higher frequencies than men. This difference was observed over all time points $(p<0.05$ for gender by ANOVA), although no differences were observed at any individual timepoint.

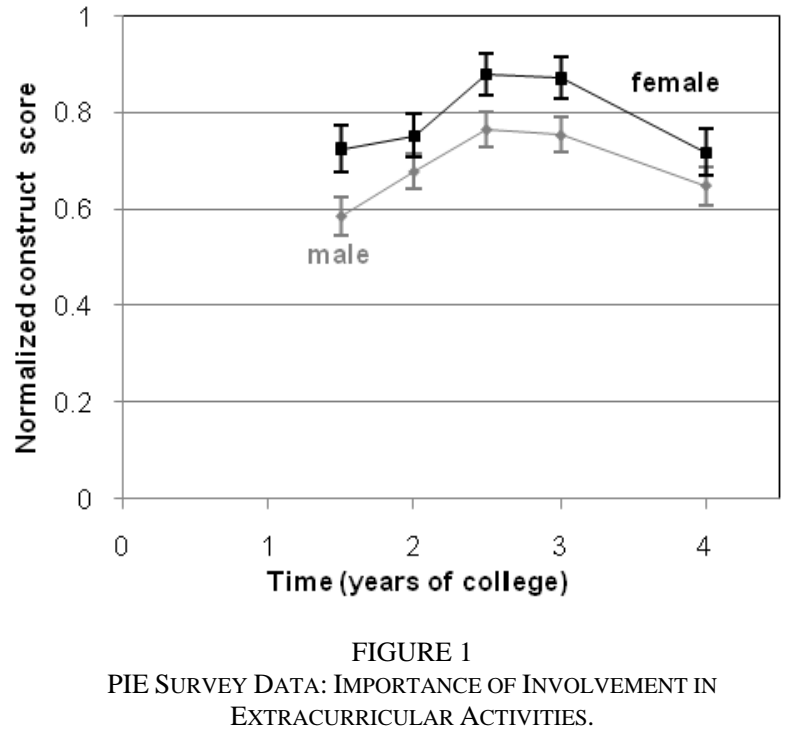

Finally, there does appear to be some temporal variation in the responses that do not appear to be genderspecific ( $<0.05$ for overall effect of time by ANOVA). For women only, the importance of extracurricular activities is higher at 2.5 and 3 years than at 1.5 and 2 years; as well, the value at 2.5 years is higher than at 4 years $(\mathrm{p}=0.005$ overall and $\mathrm{p}<0.05$ for individual comparisons). Similarly, for men, the values at 2.5 and 3 years are higher than at 1 or at 4 years $(\mathrm{p}=0.002$ overall and $\mathrm{p}<0.05$ for individual comparisons). This suggests that the importance of 
extracurricular activity, for both men and women, peaks during the junior year. In contrast to this, there is some evidence that the frequency of engaging in such activities decreases at this time. For men, the response values for frequency of extracurricular activities are lower at 2.5 and 3 years (junior year) than during the sophomore year (at 1.5 and 2 years) or the senior year $(\mathrm{p}<0.005$ overall and $\mathrm{p}<0.05$ for individual comparisons). While the responses for the female students display a very similar pattern (Figure 2), the effect of time was not statistically significant in this group, possibly due to the smaller number of respondents.

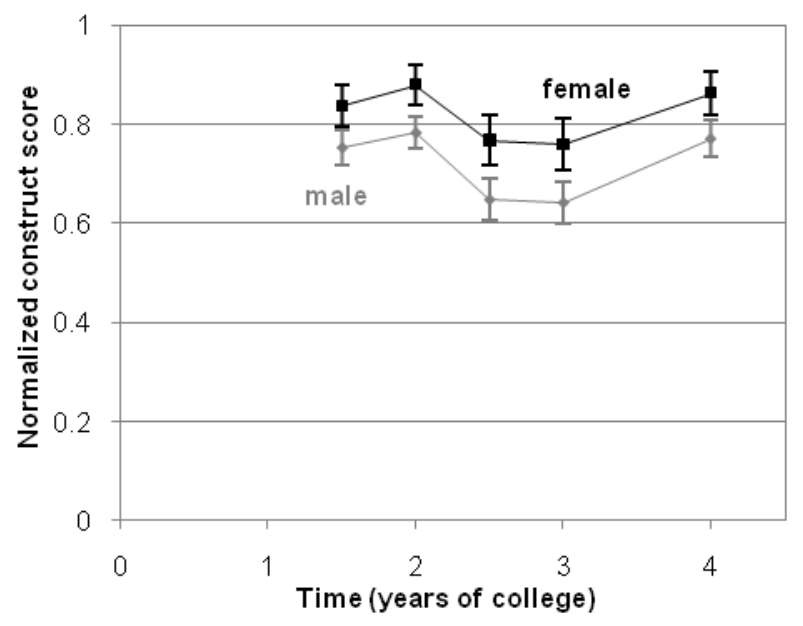

FIGURE 2

PIE SURVEY DATA: FREQUENCY OF INVOLVEMENT IN EXTRACURRICULAR ACTIVITIES.

\section{QUANTITATIVE FINDINGS: APPLES SURVEY}

Respondents to the PIE Survey came from a small group of students who were committed to studying engineering from their first academic term. While this enabled us to explore the development of these students deeply, using multiple methods, they may not be a fully representative group. The results from the PIE Survey were therefore complemented by the Academic Pathways of People Learning Engineering Survey (APPLES), a crosssectional study that shared a number of constructs with the PIE study. It consisted of a survey that was administered to more than 4000 students (first-years through seniors) at a stratified section of engineering schools across the country $[14,15]$.

The design of the APPLE Survey was closely based on the PIE Survey, with the goal of corroborating the findings of the APS on a larger scale and to expressly explore the generalizability of findings from the PIE longitudinal study to engineering students at American higher education institutions. The data and findings explored in this paper are based on a national administration of the APPLES instrument to a carefully selected, stratified sample of 21 institutions in the United States early 2008. Of the 4,266 valid responses, 3,911 students indicated they were engineering majors. We focused on the responses of these students since this group was most comparable to the longitudinal cohort who participated in the PIE study.

Respondents to the APPLE Survey were asked the two questions above regarding the importance and frequency of involvement in non-engineering extracurricular activities. In addition to those two constructs, another item on the APPLE Survey focused specifically on students' involvement in engineering-related extracurricular activities:

What is your level of involvement in student engineering activities such as engineering clubs or societies?

Response options: no involvement, limited involvement, moderate involvement, extensive involvement

Responses to items were linearly normalized to a scale of zero to one. An independent samples t-test was conducted to evaluate differences between the responses of men and women for each of the three APPLES items related to extracurricular activities. A one-way analysis of variance (ANOVA) was conducted to evaluate the role of extracurricular activities by academic standing. Significant ANOVAs were followed up with post hoc comparisons which used either the Least Square Difference (LSD) or the Games-Howell test (which does not assume equal variances among the groups). The number of male responses for each combination of construct and year (first, sophomore, junior, senior) varied from 552 to 670, and the number of female responses varied from 250 to 332. Simple correlation coefficients between responses were also calculated.

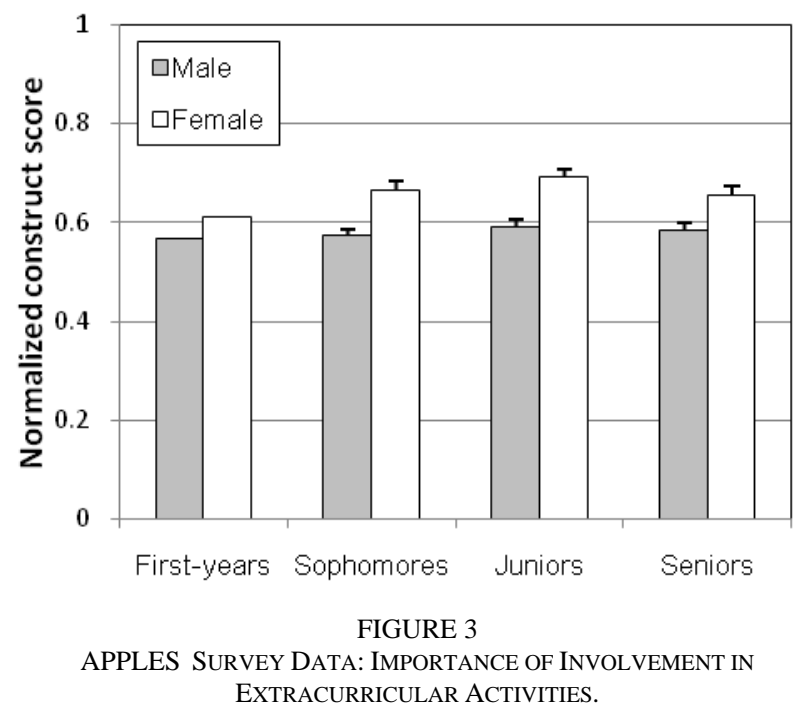

ANOVAs for women: The ANOVA was significant for importance of extracurricular activities (Figure 3; $\mathrm{p}<0.05$ ) and level of involvement in student engineering activities (Figure 5; $\mathrm{p}<0.001$ ). For the importance of extracurricular activities, post hoc comparisons using LSD showed significant differences between female first-year students and sophomores $(\mathrm{p}<0.05)$ and first-years and juniors $(p<0.01)$. For the level of involvement in student engineering activities, the Games-Howell test showed significant differences between female first-year students and juniors $(\mathrm{p}<0.05)$, first-years and seniors $(\mathrm{p}<0.001)$, 
Session T1A

sophomores and juniors $(\mathrm{p}<0.05)$, and sophomores and seniors $(\mathrm{p}<0.001)$.

ANOVAs for men: For men, no effect of time was observed for the importance or frequency of involvement in extracurricular activities (Figure 4). However, the ANOVA was significant for the level of involvement in student engineering activities $(\mathrm{p}<0.001)$. Post hoc comparisons using the Games-Howell test showed significant differences between male first-year students and the following groups: sophomores $(p<0.05)$, juniors $(p<0.001)$, and seniors $(p<0.001)$. Sophomores also differed from seniors $(p<0.05)$.

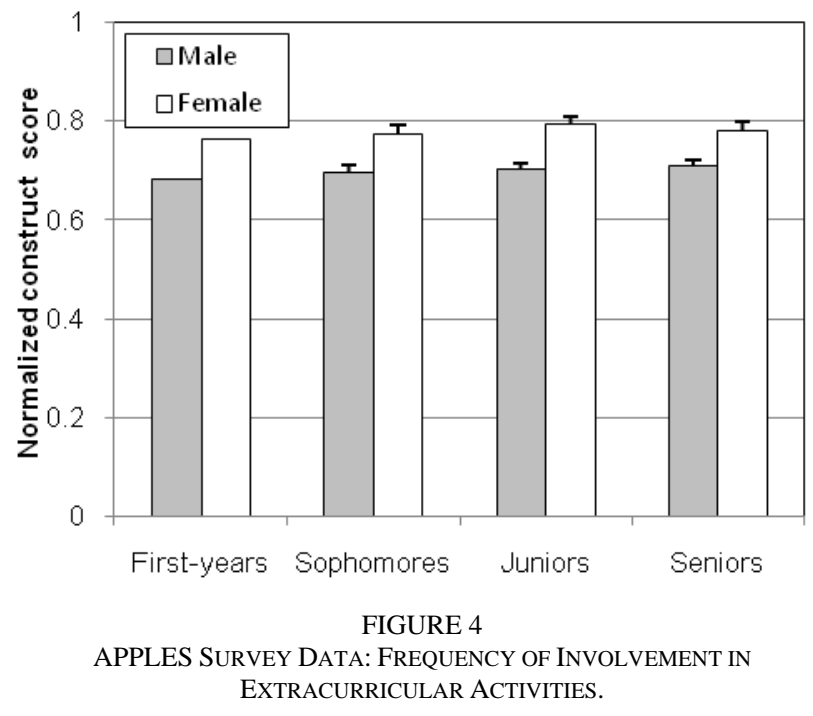

T-tests by gender: Independent samples t-tests (Table 1) between pooled data for all four years found that women reported significantly greater importance of extracurricular activities and frequency of participating in extracurricular activities than men $(\mathrm{p}<0.001)$. Women also report significantly higher levels of involvement in student engineering activities than men $(\mathrm{p}<0.001)$.

Correlations: For both genders, participation in the two types of activities are correlated $(\mathrm{p}<0.001)$, suggesting that many students participate to a similar degree in both. Involvement in engineering-related extracurricular activities is correlated with exposure to team-based projects for men $(\mathrm{p}<0.001)$, but not for women. For both genders, participation in these types of activities is correlated to increased interaction with faculty $(p<0.01$ for women, $\mathrm{p}<0.001$ for men); however, increased interaction correlates with increased satisfaction with faculty for men $(\mathrm{p}<0.001)$, but not women.

TABLE I

APPLES CONSTRUCT SCORES, BY GENDER

\begin{tabular}{cc}
\hline $\begin{array}{c}\text { Men } \\
(\text { mean } \pm \text { SD) }\end{array}$ & $\begin{array}{c}\text { Women } \\
(\text { mean } \pm \text { SD })\end{array}$ \\
\hline $0.582 \pm 0.330$ & $0.656 \pm 0.304$ \\
$0.700 \pm 0.315$ & $0.777 \pm 0.279$ \\
$0.323 \pm 0.307$ & $0.417 \pm 0.323$
\end{tabular}

Importance of extracurricular activities Frequency of extracurricular activities

Level of involvement in student engineering activities

( $n=2575$ for men, 1290 for women)

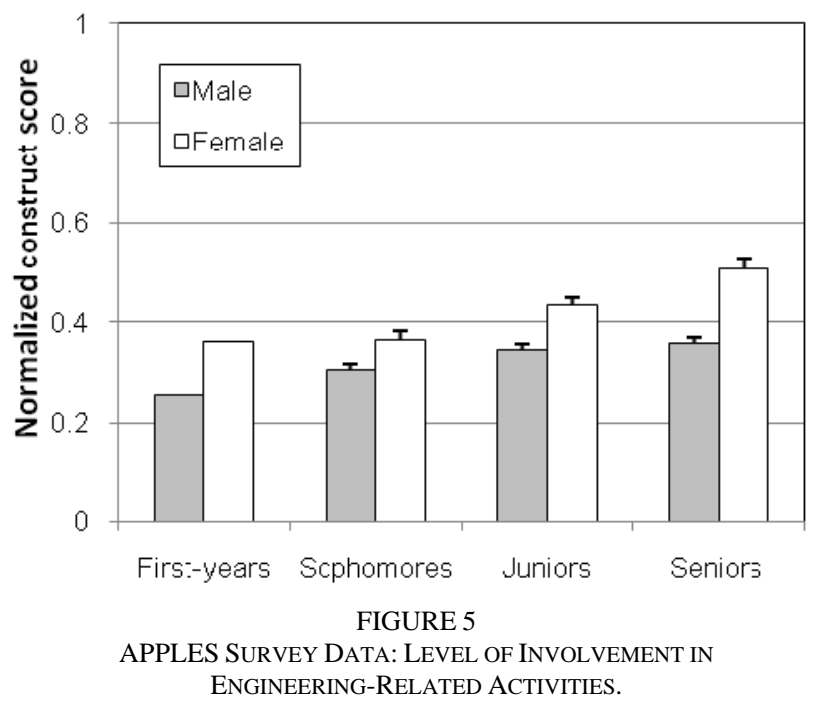

QUALITATIVE RESULTS: INTERVIEW RESPONSES

In their senior year, 15 of the APS students (5 women and 10 men) participated in an in-depth, semi-structured qualitative interview at Large Public Institution (LPI; a pseudonym). Some questions in the interview were designed to elicit reflections by students on their experiences as engineering undergraduates. Others were designed to elicit student conceptions of engineering and of themselves as engineers who were now embarking on their professional careers. In this section, we complement the findings from the PIE and APPLE surveys with a rich picture of student participation in extracurricular activities, as they described it to researchers. Data are drawn from two questions asked of students: "Are you a member of any engineering student organizations on campus?" and "Are you a member of any other student organizations on campus besides engineeringrelated organizations?" Researchers followed up these questions by asking students to identify each of the organizations they belonged to, what they thought was helpful about the organization, and the nature of their participation in the organization. Among this small sample of students, there appeared areas of commonality as well as suggestive differences between men's and women's involvement in these extracurricular organizations.

Students of both genders were likely to join a professional organization related to their engineering major, and many were also members of one or more honors societies. Membership in an honors society was a "résumé booster," according to several of the students. No active participation was required, and no one reported any significant activity related to an honors society to whom she or he belonged.

Twelve of the 15 respondents reported membership in a professional organization related to their engineering major, such as a local chapter of the Association for Computing Machinery (ACM) or the American Institute of Aeronautics and Astronautics (AIAA). Participation in engineeringrelated organizations appeared either to be minimal or very

October 18 - 21, 2009, San Antonio, TX 


\section{Session T1A}

active, with little middle ground. A minimal participation level entailed belonging to the organization and perhaps attending one or two events during the school year. Eight students (2 women, 6 men) reported belonging to an organization associated with their majors, but hardly participating. John described his level of involvement with ACM, "I signed up awhile back ago, but, you know, I go to an event here and there, but not a whole lot." Three of the men-Justin, Matthew, and Brandon-reported that they participated occasionally by attending social events sponsored by an engineering major-related organization to which they belonged. Matthew belonged to AIAA, but his perception of it was that "it's mostly a social organization, I'd say." In addition to "barbecues and stuff," the organization does offer "some [career development] opportunities, but I don't really take advantage of them.”

At the other extreme of participation, four students, three of whom were women, had been elected officers in engineering major-related organizations. Two belonged to women-focused engineering organizations-Society of Women Engineers (SWE) and ACM Committee on Women in Computing (ACMW) - and both were officers in those organizations. Lauren said being involved in SWE was helpful "because all my classes, or most of them, are majority male, so you sort of want the female connection sometimes." Elizabeth also mentioned the opportunity to meet women engineers and get career advice.

Two other men were heavily involved in engineeringrelated organizations, but not as elected officers. Austin had participated for two years in Formula SAE, an annual competition sponsored by the Society for Automotive Engineers (SAE). Austin worked with a team at LPI to design, build, and race a car in the competition. He explained that many mechanical engineering students only participated for one year in order to get credit for a senior design project, but some students participated for more than one year, and those students had important experience to add to the activity. Austin wasn't sure if his work on Formula SAE "counted" as extracurricular because he could get credit for it, but added that a lot of students volunteer without earning credit and "it's a lot of work and we spend a lot of time there" so it "helps to have an easier [course] schedule."

Jesse spent much of his free time as a member of Engineers Without Borders, where he appreciated "a little bit a sense of a different community, finding like-minded individuals" to spend time with and work for the common good. He described a variety of projects the group was designing and hoped to implement overseas in the summer. He was heading up one of the design projects, and had built a prototype.

Despite the small numbers, some interesting gender differences have emerged. Women were more likely to take on administrative leadership positions, while men's involvement in engineering-related extracurricular activity tended to be engineering-related hands-on design and prototyping. Further research on how men and women define and differentiate extracurricular activity is warranted.

In addition to engineering-related organizations, students reported being engaged in a wide range of nonengineering extracurricular activities: intramural sports, community service organizations, greek organizations, and religious student organizations. Seven of the 15 students reported participation in non-engineering extracurricular activities, six of whom reported fairly active involvement. Emily had lived in her sorority house the entire four years she attended LPI. She said it wasn't especially helpful in terms of schoolwork because there were very few engineering majors. However, "there's always something to do...it's a good place for fun.” Drew also was very involved as a leader of an off-campus activist organization for which he organized regular events. Michael's activity in a musicfocused service fraternity earned him academic credit that was not relevant to completing his engineering degree, but he found that his experience helped him develop a lot of relevant skills, like "people skills” and leadership qualities. Furthermore, he found music to be more challenging to learn than engineering, and thought this challenge was important to his growth as an engineer. "Once someone told me that...it's really important for people to fail at things in order to learn how to succeed.”

Across the range of engineering and non-engineering extracurricular activities that individual students engaged in, there are some interesting groupings. The three women who had been elected officers of engineering-related professional organizations also reported moderate to heavy participation in other extracurricular activities or organizations. Six of the ten men reported generally high activity in extracurricular organizations, but most focused their efforts in one organization. Only Drew reported significant involvement in more than one activity: leadership of the off-campus activist group, as well as intramural sports. Again, the numbers are too small to make any assertions with certainty, but these data suggest a gender difference in which women's involvement often is spread across more than one activity, where men's involvement tends to be focused on one intense activity. This may be another reason for the differences between men and women's involvement in extracurricular activities as reported in the PIE and APPLES surveys. Further research would reveal whether there are patterns in men's and women's engagement in extracurricular activities, and why such patterns exist.

\section{DISCUSSION}

Based on the quantitative data, women report participating in both engineering-related and unrelated extracurricular activities to a greater degree than men. For both genders, participation in the two types of activities are correlated $(\mathrm{p}<0.001)$, suggesting that many students participate to a similar degree in both. Findings from interviews seem to support this correlation and the greater involvement of women, who tend to be actively involved in 
more than one activity or organization; men tend to be focused on a single activity.

The greater levels of involvement of women in engineering extracurricular activities of women were also borne out in our qualitative research. In this sample, three of the four officers (that is, highly active participants) in engineering-oriented extracurricular activities were women. However, in engineering activities, women tended to take on leadership roles and men tended to be more involved in "hands-on" activities such as design and prototyping. This may help explain why involvement in engineering-related extracurricular activities is correlated with exposure to team-based projects for men $(\mathrm{p}<0.001)$, but not women.

Extracurricular activities can play an important role in exposing undergraduate engineering students to broader challenges that enable them to utilize or complement their disciplinary knowledge (or both). Fostering integrative learning "across courses, over time, and between campus and community life" [16] has been highlighted as an important goal of undergraduate education. In particular, as we prepare students to address global engineering challenges, they may benefit from experiences that occur outside the classroom, as well as those that occur within it. Understanding the role of extracurricular activities in the development of undergraduate engineering students, as well as understanding differences in how male and female students perceive and engage in these activities, is important in supporting student growth and development.

\section{ACKNOWLEDGMENT}

The authors would like to acknowledge the contributions of the following individuals: Krista Donaldson, Gary Lichtenstein, and George Toye of Stanford University, and Özgür Eris of the Franklin W. Olin College of Engineering, for their collective efforts toward developing and administering the Persistence in Engineering and APPLE Surveys; Camelia Rosca and Larry Ludlow of Boston College for statistical analyses of the survey data; and Cynthia J. Atman and Ken Yasuhara, and Yi-Min Huang of the University of Washington for their involvement in obtaining and analyzing the interview data.

The Academic Pathways Study is supported by the National Science Foundation under Grant No. ESI-0227558 which funds the Center for the Advancement of Engineering Education (CAEE). CAEE is a collaboration of five partner universities: University of Washington, Stanford University, Howard University, Colorado School of Mines, and University of Minnesota.

\section{REFERENCES}

[1] A. Astin, Achieving Educational Excellence: A Critical Assessment of Priorities and Practices in Higher Education. San Francisco, CA: JosseyBass, 1985.

[2] V. Tinto, "Dropout from higher education: a theoretical synthesis of recent research," Review of Educational Research, vol. 45, pp. 89-125, 1975.

[3] V. Tinto, Leaving College: Rethinking the Causes and Cures of Student Attrition. Chicago: University of Chicago Press, 1987.
[4] E. T. Pascarella and P. T. Terenzini, How College Affects Students vol. 2. San Francisco, CA: Jossey-Bass, 2005.

[5] G. D. Kuh, J. Kinzie, J. H. Schuh, and E. J. Whitt, Student Success in College. San Francisco, CA: Jossey-Bass, 2005.

[6] M. W. Ohland, S. D. Sheppard, G. Lichtenstein, O. Eris, D. Chachra, and R. A. Layton, "Persistence, engagement, and migration in engineering programs.," Journal of Engineering Education, vol. 97, pp. 259-278, 2008. [7] S. Sheppard, C. J. Atman, R. Stevens, L. Fleming, R. Streveler, R. Adams, and T. Barker, "Studying the engineering student experience: design of a longitudinal study," in American Society of Engineering Education Annual Conference Salt Lake City, UT, 2004.

[8] M. Clark, S. Sheppard, C. J. Atman, L. Fleming, R. Miller, R. Stevens, R. Streveler, and K. Smith, "Academic Pathways Study: Processes and realities," in American Society of Engineering Education Annual

Conference Pittsburgh, PA, 2008.

[9] J. W. Creswell, V. L. P. Clark, M. L. Gutmann, and W. E. Hanson, "Advanced mixed methods research designs," in Handbook of Mixed Methods in Social and Behavioral Research, A. Tashakkori and C. Teddlie, Eds. Thousand Oaks, CA: Sage, 2003.

[10] R. B. Johnson and A. J. Onwuegbuzie, "Mixed methods research: a research paradigm whose time has come," Educational Researcher, vol. 33, pp. 14-26, 2004.

[11] H. Chen, K. Donaldson, O. Eris, D. Chachra, G. Lichtenstein, S. Sheppard, and G. Toye, "From PIE to APPLES: the evolution of a survey instrument to explore engineering student pathways," in American Society for Engineering Education Annual Conference Pittsburgh, PA, 2008.

[12] Ö. Eris, H. Chen, T. Bailey, K. Engerman, H. Loshbaugh, A. Griffin, G. Lichtenstein, and A. Cole, "Development of the Persistence in

Engineering (PIE) survey instrument," in American Society for Engineering Education Annual Conference Portland, OR, 2005.

[13] Ö. Eris, D. Chachra, H. Chen, C. Rosca, L. Ludlow, S. Sheppard, and K. Donaldson, "A preliminary analysis of correlates of engineering persistence: results from a longitudinal study," in American Society for Engineering Education Annual Conference Honolulu, HI, 2007.

[14] K. Donaldson and S. Sheppard, "A Snapshot of American Undergraduate Engineering Institutions: National Sampling for the Academic Pathways of People Learning Engineering Survey (APPLES)

(Academic Pathways Study)," Center for the Advancement of Engineering Education, 2008.

[15] K. Donaldson, H. L. Chen, G. Toye, M. Clark, and S. Sheppard, "Targeting undergraduate students for surveys: lessons from the Academic Pathways of People Learning Engineering Survey," in Frontiers in Education Milwaukee, WI, 2007.

[16] M. T. Huber, C. Brown, P. Hutchings, R. Gale, R. Miller, and M. Breen, "Integrative Learning: Opportunities to Connect. Public Report of the Integrative Learning Project sponsored by the Association of American Colleges and Universities and The Carnegie Foundation for the Advancement of Teaching," Stanford CA, 2007.

\section{AUTHOR INFORMATION}

Debbie Chachra, Franklin W. Olin College of Engineering, Needham, MA; debbie.chachra@olin.edu.

Helen L. Chen, Stanford Center for Innovations in Learning, Stanford University, Stanford, CA; hlchen@stanford.edu.

Deborah Kilgore, Center for Engineering Learning and Teaching, University of Washington, Seattle, WA; kilgored@u.washington.edu.

Sheri Sheppard, Dept. of Mechanical Engineering and Center for Design Research, Stanford University, Stanford, CA; sheppard@stanford.edu. 